\title{
UMA HISTÓRIA (ROMANCEADA) DA LITERATURA BRASILEIRA
}

Maria Eunice Moreira*

\begin{abstract}
RESUMO: Proposta de escrita de uma história da literatura, a partir de um corpus constituido por romances brasileiros publicados nas últimas décadas do século $\mathrm{XX}$, que tomam como personagens da ficção autores de literatura brasileira, que viveram e produziram em diferentes periodos de nossa história.
\end{abstract}

PALAVRAS-CHAVE: Romance; história da literatura.

\section{A Moldura Teórica}

U um texto intitulado "História da literatura e narração"1, 1 presente em seu livro É possivel a história literária?, o historiador norte-americano David Perkins parte do pressuposto de que, embora seja incomum pensar a história da literatura como uma narrativa histórica, tal reflexão não só é legivel, como exeqüivel. Segundo ele, isso é possivel, por, pelo menos, duas justificativas: a) a história da literatura preenche os critérios essenciais da narrativa; b) a história da literatura descreve a transição, através do tempo, de um estado de coisas a outro, diferente, valendo-se da voz de um narrador, no caso, o narrador do texto historiográfico. Nessa perspectiva, ele analisa a história da literatura como uma narrativa

* Pontifícia Universidade Católica do Rio Grande do Sul - PUCRS.

PERKINS, David. História da literatura e narração. Cadernos do Centro de Pesquisas Literárias da PUCRS, Porto Alegre, v. 3, n. 1, mar. 1999. Série Traduçōes. 
e, ao propor uma história narrativa da literatura, procura delimitar os elementos presentes nas narrativas tradicionais.

Perkins chama a atenção que uma história narrativa da literatura "pode usar apenas formas tradicionais de narrativa"2, não tendo até agora utilizado "formas modernistas de narração"3. Narrativas tradicionais têm começos, fins e enredos que ligam seus pontos, formando um todo coeso, que escapa ao padrão das narrativas contemporâneas. Isso porque, ensina o historiador, a narrativa histórica literária deve deixar a imaginação do leitor restrita a uma pequena esfera de ação: não só o enredo é limitado, como também os eventos narrados devem ser coesos e as interpretações, potencialmente abertas, necessitam ser fechadas por argumentos coerentes e sólidos, que limitem a capacidade de imaginação do leitor. Se deixasse ao leitor o exercício da imaginação, a história da literatura poderia se confundir com a narrativa ficcional, comprometendo sua característica historiográfica. É por isso que os modelos tradicionais tornam-se mais adequados à história narrativa da literatura: as técnicas de ficção modernas e pós-modernas desenvolvem-se em oposição ao modelo tradicional, problematizando justamente o arranjo desse modelo e estimulando exercícios mentais em que o sujeito da leitura torna-se também ele criativo e é convocado para completar a tarefa do ficcionista.

Ao discutir a organização do arranjo, isto é, ao propor a história da literatura como um arranjo com início, meio e fim, Perkins salienta que o início e o fim de uma história literária são freqüentemente artificiais. O historiador necessita descrever o ponto de partida de sua história, mas esse princípio não é idêntico para todos os historiadores. Se se tomar, por exemplo, o mesmo evento o Romantismo - seu momento inaugural, no Brasil, pode trazer controvérsias ou diferenças. Conta-se a história do Romantismo

\footnotetext{
2 Idem, p. 3.

3 Idem, p. 3.
} 
Rev. ANPOLL, n. 16, p. 225-240, jan./jun. 2004.

desde 1836, quando Gonçalves de Magalhães publica Suspiros poéticos e Saudades, ou conta-se a história do movimento em sua vinculação ao Império nacional, cuja história poderia ser mais tardia, e começar apenas quando o mesmo poeta lança a epopéia $A$ confederação dos Tamoios, em 1856, texto cuja publicação foi patrocinada pelo Imperador D. Pedro II?

Embora divergente, o começo tem um impacto muito grande sobre o passado literário, correspondendo ao ato de fundação, ao mito de origem, do fenômeno que é relatado. Assim, antes da obra primeira e inaugural, é comum que o historiador descreva a situação desordenada em que as letras se movimentavam, remontando, portanto, a uma fase caótica, para conceder ao começo um sentido cosmogônico, isto é, organizado, ao passado. Nessa perspectiva, o primeiro relato conforma-se segundo um mito de criação e institui o fenômeno, funcionando como um ponto de partida para os sucessos ou empreendimentos posteriores. Arbitrário ou artificial, o começo exige um final que é também tão artificial ou arbitrário quanto os momentos inaugurais. Por isso, a história se fecha por um outro evento, definido pelo historiador como conclusivo. O exemplo trazido por Perkins é significativo: segundo ele, a história do drama elizabetano termina com o fechamento do teatro em 1642. O dado, de caráter social, remete ao fim do movimento dramático, quando é possivel constatar que o encerramento do teatro não provocou a morte e o desaparecimento do gênero, que continuou a se transformar e a sofrer mutações para além de uma mera data.

A arbitrariedade desses limites - começo e fim - é imposta, segundo Perkins, porque a história narrativa da literatura desenvolve-se em torno de uma figura central - o herói da narrativa, elemento que se transforma no tempo. O herói não é uma pessoa, mas um indivíduo social ou um assunto. Dele, toma-se um momento de sua existência como início (o aparecimento de uma obra) e um outro subseqüente como final (o lançamento de outra obra, por exemplo). Em outras palavras, do estado inicial dos aconteci- 
mentos mostra-se como o herói chegou ao final. No primeiro momento, "o estado interior ou exterior do herói não é o mesmo que foi no primeiro e o meio da narrativa é responsável por essa mudan-

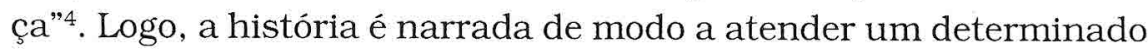
enredo, fixado pelo historiador. Nesse processo de enredar o passado, o historiador promove seus heróis e elimina seus oponentes, acentua rivalidades, ameniza rancores, com o fim de sustentar a vitalidade do herói escolhido. Esse, tal qual uma pessoa, nasce, desenvolve-se e morre, pela mão criadora do historiador.

Ficção ou história da literatura? Verdade ou mentira? A narrativa histórica difere da ficção porque, ao construir o texto literário, o enredo prevalece sobre a história, diz Perkins. Ao historiador, ao contrário do romancista, não será permitido inventar acontecimentos no nível da história e se os mesmos eventos engendram histórias da literatura diferenciadas, não significa que sua estrutura esteja rompida. Qualquer história da literatura preservará os fatos na sucessão cronológica de seu aparecimento e, ainda que a narrativa literária seja a narrativa das leituras do passado (e não dos fatos), o discurso historiográfico continua a responder por uma "dose" de história que concede a ela o estatuto histórico. Cabe ao historiador - e sobretudo ao historiador da literatura estar atento a esses movimentos e explicitar os critérios utilizados para sua escrita, o signo condutor de sua história, o herói que a movimentará e as balizas temporais em torno das quais organizará o seu mundo.

Do quadro teórico, decorrem algumas providências que competem ao narrador da história literária para iniciar seu percurso. Três etapas devem ser atendidas:

a) a primeira fase destina-se a "fazer a crônica, isto é listar em ordem cronológica os trabalhos ou outros acontecimentos que

Idem, p. 3. 
Rev. ANPOLL, n. 16, p. 225-240, jan./jun. 2004.

pertencem ao periodo de tempo relevante" ${ }^{5}$. Isso o leva a pro ceder ao levantamento dos fatos e eventos que constituirão a matéria da sua história: romances ou poesias, diários ou epís tolas; informações estatísticas sobre leitores e livros mais lidos; condições de recepção das obras; material crítico;

b) a fase seguinte destina-se a "desenhar uma estória (story) dentro

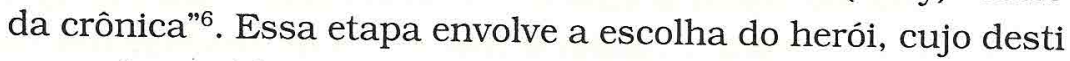
no será seguido, os marcos temporais da narrativa, isto é, é necessário estabelecer o princípio e o fim da história, deline ando o panorama temporal em que os eventos ocorrem;

c) a última fase destina-se à definição e construção da narrativa. Nesse momento, o historiador precisa encontrar um arquétipo, reconhecível pelo leitor, em torno do qual organizará seu texto. Desse modo, a ascensão e a queda, a vitória e a derrota, a dis puta e a conciliação podem tornar-se os elementos arranjadores da narrativa, mas é preciso que o leitor os reconheça como tal, para que a história faça sentido. A tal arranjo interpretativo Perkins denomina enredo, esclarecendo que ele é conformado pela seleção de incidentes do autor, ou seja, "por suas decisões sobre que eventos, na cronologia, vai enfatizar, representar, men cionar de leve ou omitir". ${ }^{7}$

A história narrativa da literatura, como a entende David Perkins, constrói-se de modo linear e seletivo, valendo-se do fio do tempo para arrumar os eventos. No entanto, não basta apenas o arranjo temporal - é preciso aproximar os elementos, atribuirlhes um sentido, evitando lacunas ou contradições, pois se a história da literatura paga seu tributo à narrativa, necessita também manter seu compromisso com a história. Só assim, com um pé na

Idem, p. 17.

Idem, p. 18.

Idem, p. 18. 
literatura e outro na história ela poderá realizar seu intento e disputar seu lugar entre os estudos literários.

\section{Uma história da literatura}

Tentando seguir a lição de David Perkins e visando aplicá-la à literatura brasileira, minha intenção é a de recortar um corpus que entrelaça história e literatura, mas que se estreita na medida em que o objeto da história narrada é o próprio escritor. O corpus de que falo é constituído por um conjunto de romances, publicados nos últimos anos no Brasil e que, curiosamente, tomam como personagens da ficção autores de literatura brasileira, que viveram e produziram em diferentes períodos de nossa história. Desse modo, procurando cumprir com a primeira lição do professor americano, seleciono a matéria que será objeto da minha história - o romance brasileiro - representado pelas seguintes obras, apresentadas na ordem cronológica de aparecimento:

1. Calvário e porres do pingente Afonso Henriques de Lima Barreto, de João Antônio - 1977

2. Em liberdade, de Silviano Santiago - 1981

3. Os cães da Província, de Luiz Antonio de Assis Brasil - 1987

4. O boca do inferno, de Ana Miranda - 1989

5. A barca dos amantes, de Antonio Barreto - 1990

6. A dança da serpente, de Sebastião Martins - 1991

7. Memorial do fim: a morte de Machado de Assis, de Haroldo Maranhão - 1991

8. Os rios turvos, de Luzilá Gonçalves Ferreira - 1992

9. A última quimera, de Ana Miranda - 1994

10. O primeiro brasileiro, de Gilberto Vilar - 1995

11. Clarice, de Ana Miranda - 1996 
Rev. ANPOLL, n. 16, p. 225-240, jan./jun. 2004.

\section{Bilac vê estrelas, de Ruy Castro -2000}

e o mais recente, 13 - Dias e dias, de Ana Miranda -2002.

À cronologia de lançamento, opto por outra, procurando estabelecer uma relação temporal com o elenco antes mencionado. A segunda lição de Perkins ensina que devem ser determinados os marcos temporais, visando definir o início e o fim da narrativa. A história começa, então, no período colonial brasileiro, com o poeta Bento Teixeira e sua obra Prosopopéia, publicada em Lisboa, em 1601, e fecha-se, em 1996, com a narrativa de Ana Miranda, invocando a figura enigmática da escritora Clarice Lispector, já nos nossos contemporâneos tempos.

$O$ enredo da narrativa necessita levar em conta os fatos relatados, que abrangem uma faixa temporal bastante ampla - quatro séculos de história - e que contam diferentes situações vividas por esses sujeitos históricos, mas também sujeitos ficcionais. Senão vejamos:

1 - O periodo colonial brasileiro inscreve-se com dois romances: Rios turvos, de Luzilá Ferreira e O primeiro brasileiro, de Gilberto Vilar, que enfocam a vida do poeta luso-brasileiro Bento Teixeira e a criação de seu poema Prosopopéia. Figura quase relegada da historiografia literária, que não concede lugar definido ao autor - português ou brasileiro? judeu ou cristão novo? - ou a seu poema laudatório aos Albuquerques, do Recife, Bento é apresentado nas contingências históricas de um Brasil que se deixa enredar nos laços da Inquisição, como um escritor que se debate entre provar a sua inocência frente ao tribunal inquisitório e autor de um texto original e bem talhado por sua mulher Filipa Raposa. Metáfora das relações de um país no momento de seu nascimento, zona de disputa entre dois poderes - o civil e o religioso, Bento é tecido e enredado por sua mulher, a fulgurante Raposa, que não só o confronta na arte de versejar (ela seria mais hábil e astuta), como o condena ao Santo Ofício. Livre do fogo da condenação, resta ao poeta consumir-se pela doença, como forma de se purificar dos pecados cometidos contra a religião e contra 
Moreira, Maria Eunice. Uma história (romanceada) da literatura brasileira.

sua mulher (o assassinato de Filipa transforma Bento num uxoricida), cujo final de vida transcorre em Portugal, condenado pelo resto dos dias a usar o sambenito, o hábito de baeta amarela e verde, que os penitentes trajavam nos autos-de-fé.

2 - Esse mesmo periodo histórico, mas num outro foco de ação, a Bahia do século XVIII, é o palco onde vivem dois importantes homens da literatura colonial barroca: o satírico poeta Gregório de Matos Guerra, o destemido boca do inferno, que tudo diz e revela, contracena com o não menos famoso Padre Antônio Vieira, no livro Boca do inferno, de Ana Miranda. A Bahia do periodo colonial desnuda-se numa narrativa entremeada de citações do poeta, que colaboram para organizar o tecido narrativo do romance. Ana Miranda e Gregório de Matos parecem compor, a quatro mãos, um romance sobre a vida na cidade mais famosa do Brasil, capital do Império, a cidade do Salvador, em que nobres e plebeus disputam o pequeno espaço social conhecido como Brasil, do qual sua capital funciona como um espécie de metonímia do perturbado quadro histórico-político de um país incipiente. Narrativa de origem dos vícios e mazelas nacionais, em Boca do inferno demarca-se o território das ações corruptas e misteriosas que encenam a história brasileira.

3 - Ao periodo da vida baiana, a história brasileira e a história da literatura deslocam-se de Salvador para a região das Minas, em função do ciclo aurífero, que passa a centralizar a vida econômica e, por conseqüência, a cultura nacional. Nesse momento, no final do século XVII, dois romances focalizam os novos ares vividos pelo país, trazendo à cena Tomás Antônio Gonzaga, o poeta árcade Dirceu e sua musa, a bela Maria Dorotéa de Seixas, ou simplesmente Marília. $O$ encontro entre os dois amantes e os bastidores da revolta dos inconfidentes compõem o texto $A$ barca dos amantes, de Antônio Barreto. O jogo ficcional invoca a lenda sueca de título homônimo: quando duas pessoas se amam, diz o relato mítico, devem guardar na barca dos amantes os seus sonhos. Guando o amor se vai, a barca precisa ser lançada ao mar, para que os deuses da água se 
Rev. ANPOLL, n. 16, p. 225-240, jan./jun. 2004.

encarreguem de transportar os sonhos que um não revelou ao outro, causa da desdita amorosa. Envolvidos nessa atmosfera lendária, transitam também outras personagens literárias e históricas que viveram o período da insurreição mineira, num jogo de vinganças, malversões administrativas e amores fraudados, que enchem as páginas do texto e acompanham o romance frustrado de Gonzaga, em Minas, até sua prisão e chegada à África, como degredado.

Outro poeta desse mesmo período e participante da conjuração mineira - Alvarenga Peixoto e sua esposa Bárbara Heliodora, movimentam-se em A dança da serpente, de Sebastião Martins. Centrado na deslumbrante Bárbara Heliodora, de comportamento e mente livres e selvagens, mas lúcida e crítica, num tempo em que às mulheres cabia apenas a subordinação ao homem (primeiro ao pai e depois ao marido), o livro mostra Bárbara como a musa de um poeta mais velho do que ela, como também, de certa forma, a heroina de uma revolta (a própria insubordinação política, mas de outra, mais silenciosa, a do feminismo do século $\mathrm{XX}$ ). Os bastidores da inconfidência, entre as intrigas dos dirigentes e o idealismo dos poetas, mesclam-se para caraterizar a sociedade brasileira às vésperas de sua explosão.

4 - O século XIX marca sua presença com o romance de Luiz Antonio de Assis Brasil, Os cães da Província, deslocando o centro das atenções do espaço das Minas Gerais para o território extremo da nação, o Rio Grande do Sul. Na Capital da Província sulina, em meados do século, transcorrem episódios inusitados: um açougueiro da rua do Arvoredo, no centro da cidade, produz embutidos (lingüiças) de muito boa qualidade, reconhecidos e solicitados pela população. A origem da qualidade do produto é posteriormente descoberta: trata-se de carne humana, oriunda dos crimes cometidos pela sensual mulher do comerciante. É no palco desses acontecimentos, que envolvem autoridades rio-grandenses, que entra em cena o excêntrico professor, comerciante, funcionário público, escritor, Qorpo Santo, cujo nome recebe esse apodo em função do 
MoreIra, Maria Eunice. Uma história (romanceada) da literatura brasileira.

periodo em que o cidadão José Joaquim de Campos Leão (seu nome verdadeiro) esteve apartado do mundo das mulheres. Vindo de Triunfo para Porto Alegre, Gorpo Santo vive na Capital do Rio Grande com a mulher e filhos, inicialmente, até o pedido de separação apresentado pela esposa, em função de sua demência. Autor de um conjunto de quase vinte comédias, escritas num lapso de tempo exíguo (aproximadamente dois anos), que jorram de sua mente como num surto psicótico, numa escrita que objetiva recuperar uma particular fonética, o dramaturgo é levado para o Rio de Janeiro, para tratamento mental, lá recebe atestado de sanidade e volta para Porto Alegre. Os episódios de existência comprovada servem como pano de fundo para a discussão dos tênues limites entre a sanidade e a doença de um homem, colocado ao lado daqueles que, considerados normais, são capazes de perpetrar as ações mais hediondas. $O$ livro aponta, ainda, para as mudanças anotadas na sociedade brasileira da segunda metade do século XIX, quando chegam ao País as doutrinas cientificistas em voga na Europa, presentes na obra através das teses de dois médicos, divergentes quanto ao tratamento preconizado para a loucura.

5 - É ainda no século XIX, que Ana Miranda busca o poeta Antônio Gonçalves Dias para escrever seu mais recente romance Dias e dias. Narrada por Feliciana, jovem que nutre um amor platônico pelo poeta, a vida do escritor é revelada através das cartas que ele enviara a seu amigo Alexandre Teófilo Leal, passadas à Feliciana por Maria Luiza, esposa de Teófilo. Reescrevendo a trajetória pessoal de Gonçalves Dias, o romance também desvenda uma outra geografia do Brasil, que vai do centro ao norte do país (Caxias, no Rio de Janeiro, onde começa a narrativa a São Luís do Maranhão onde se dá seu desfecho) e uma outra tipologia humana: índios, negros, mamelucos e cafuzos dão conta da mestiçagem que compõe a sociedade brasileira, enquanto militares, professores, pequenos comerciantes, que fazem o círculo da vida pública, ajustam-se ao ambiente privado da família e denotam as relações que se estabelecem numa sociedade que quer ser brasileira, mas mantém seus laços com a antiga me- 
Rev. ANPOLL, n. 16, p. 225-240, jan./jun. 2004.

trópole. O pai de Feliciana e sua afeição pelos sabiás é representativo do mundo de cá (a América), mundo do qual se aparta o poeta para chorar e compor a "Canção do exílio". Sintomaticamente, é esse o poema de onde a autora colhe a epígrafe para o livro e é esse também o texto que transita pelas páginas de Dias e dias, retocando, assim, o tom nacionalista dos versos do poeta romântico.

6 - O fim do século XIX produziu seu romancista mais famoso Machado de Assis, figura central do romance de Haroldo Maranhão, O memorial do fim, subintitulado A morte de Machado de Assis. Num exercício mimético com a prosa machadiana, Haroldo Maranhão expõe o autor de Memórias póstumas em seus últimos dias, atualizando personagens, situações e a própria obra do Bruxo do Cosme Velho.

7 - Na cidade do Rio de janeiro, em 1903, nos anos inicias do novo século, vivia o poeta Olavo Bilac, freqüentando os espaços mais famosos da Capital federal, como a Confeitaria Colombo, rodeado de seus pares, que a ele concediam o lugar de primazia. Poeta consagrado, o autor dos famosos versos sobre as estrelas, preocupavase mais em brilhar e discutir os temas candentes de seu tempo: o saneamento da cidade, as primeiras experiência automobolísticas ou o preço de um quadrinha que compunha como reclame para os novos produtos de consumo, do que propriamente a arte literária. Envolvido numa trama da qual participa também o jornalista abolicionista José do Patrocínio e o inventor Santos Dumont, Bilac vê estrelas coloca o poeta numa ação trágico-cômica com um dirígivel, inventado por José do Patrocínio e cobiçado por uma espiã francesa e um padre sensual, que acaba por derrubar sua auréola e o mito em torno de seu nome, no livro de Ruy Castro.

8 - Os primeiros anos do século XX estão registrados em Calvário e porres do pingente Afonso Henriques de Lima Barreto, texto que mescla a ficção do autor de Memórias do escrivão Isaías Caminha com a inventiva de João Antônio. Segundo seu autor, o roteiro dos bares urbanos, freqüentados por Lima Barreto, em torno dos quais se or- 
Morerra, Maria Eunice. Uma história (romanceada) da literatura brasileira.

ganiza a narrativa, lhe foram passados no Sanatório da Muda da Tijuca pelo professor Carlos Alberto Nóbrega da Cunha, homem tido e havido como caduco, maníaco e esclerosado, que conheceu Lima Barreto em vida. O depoimento desse cidadão, que fora o diretor político do Diário de Notícias, foi feito a João Antônio, na idade de setenta e dois anos. É esse relato que o narrador transfere ao leitor, na ilusão de transmitir a palavra viva desse observador do passado. 9 - A última quimera, de Ana Miranda (outro livro sobre os primórdios do século $\mathrm{XX}$ ), trata da vida de um poeta marginalizado, Augusto dos Anjos, em que Olavo Bilac volta novamente à ribalta. Os anos inaugurais do novo século são narrados em torno de suas características mais marcantes: a disputa do espaço urbano pelo automóvel que trafegava ao lado do tílburi puxado a cavalo, os projetos de reurbanização de uma Capital onde viviam os últimos representantes de uma Belle Époque boêmia e as disputas políticas e literárias que marcaram esses anos: a revolta da Chibata, no plano histórico, ou o duelo entre Olavo Bilac e Raul Pompéia, que afetou o espaço literário. Nesse quadro moderno, vive o poeta Augusto dos Anjos, dado a lucubrações metafísicas e reflexões sobre a objetividade do cientificismo. Escritor gauche-gauche na vida particular, pois morreu pobre, legando à familia apenas os exemplares encalhados de seu único livro Eu, Augusto dos Anjos foi também um gauche na profissão - professor do Estado, viu-se sempre à procura de um emprego para sustentar mulher e filhos, até seus últimos dias, numa cidadezinha interioriana de Minas Gerais, para onde se transferiu por recomendações e favores. Deslocado na sociedade e posto em contraste com o afamado poeta das estrelas, a trajetória de Augusto dos Anjos realiza-se apenas como uma quimera, apenas como uma broma, uma brincadeira de vida e de arte.

10 - A ficção de Silviano Santiago, Em liberdade, movimenta três tempos e três escritores, que presentificam o passado da história e da literatura brasileiras, num jogo especular em que um é o outro, mas todos são Silviano. Fala mais alto, aqui, o professor de literatu- 
Rev. ANPOLL, n. 16, p. 225-240, jan./jun. 2004.

ra que se vale de Graciliano Ramos e de Cláudio Manuel da Costa para discutir as questões atuais de uma aula de literatura (história da literatura): do campo da literatura, a metaficção, a concepção de autoria, a obra literária, a recepção, a leitura; do campo da história, os problemas da censura, da repressão, dos enganos e subterfúgios em que a sociedade historicamente vive, na moldura histórica de um Brasil pós-moderno, que se cruza entre o barroco e a modernidade; do campo da historiografia, a relação entre os diferentes passados que se apresentam, na narrativa do presente, como presentes desse passado. Nesse caso, Silviano lê Graciliano, que lê Cláudio, e todos se unificam nesse quadro do Brasil pós-64. A leitura possibilita reconhecer tanto a colônia sequiosa pela liberdade do periodo da inconfidência, o Brasil da ditadura Vargas em que mecanismos coercitivos exerciam sua força ou o Brasil da atualidade que se debate entre os problemas mal resolvidos de sua identidade, para neles colocar um intelectual que discute com o poder do Estado.

11 - A relação se fecha com Clarice, curiosamente publicado na primeira edição, de 1996, pela Relume Dumará, com o subtítulo “o tesouro de minha cidade". O livro focaliza a autora de Perto do coração selvagem em sua relação com a cidade do Rio de Janeiro, mais especificamente com o bairro do leme, onde a escritora passou grande parte de seus dias. Clarice é uma mulher comum que vai à praia, transita pelas ruas, pensa em suas roupas, nos móveis de sua casa, na sua alimentação; uma mulher que anda de ônibus, que escreve seus textos à máquina, que tem os dedos queimados pelo cigarro; uma mulher que sofre: sofre sua condição feminina, sofre seu silêncio e sofre também pelas palavras que profere. Clarice adulta rememora sua origem, a infância, os constantes deslocamentos de um lugar ao outro do Brasil: do Nordeste ao Rio de Janeiro. Enfim, há uma Clarice criança e uma Clarice adulta e todas transitam pelas páginas da narrativa. Tudo isso pode ser Clarice, a escritora, porque a história dessa personagem parece se confundir com a história da autora identificada como Clarice Lispector, mas tudo 
MoReIRA, Maria Eunice. Uma história (romanceada) da literatura brasileira.

isso pode ser uma criação ficcional, uma invenção, em que apenas o nome da personagem é emprestado da verdadeira Clarice. Portanto, o livro não é sobre Clarice Lispector, mas uma ficção de Ana Miranda, em pleno poder e exercício da literatura.

Fechado o ciclo, restam algumas (poucas) observações sobre o material apresentado e que visam atingir a terceira e última lição de Perkins, qual seja, a de encontrar um arquétipo, reconhecível pelos leitores, que possa dar sentido à narrativa.

1 - A história da literatura nasce no momento em que a antiga colônia portuguesa visava definir seus contornos para garantir sua autonomia em relação à metrópole e confunde-se com a história da ascensão e reconhecimento da manifestação de uma expressão de caráter nacional na literatura. O herói que conduz a narrativa é a "identidade nacional". A expressão amplia o sentido da "cor local" porque traduz a capacidade que a literatura tem de representar o mundo natural, mas significa também a relação entre esse espaço particular e o país em que ele se tornou. A história narrativa da literatura pode ser lida como a história em direção à autonomia do fazer literário., buscando definir contornos nitidos para o que se denomina "Literatura brasileira".

2 - Do ponto de vista da história da literatura, o elenco sinaliza para a formação de um cânone literário, em que os autores e as obras selecionadas confirmam sua presença na linha do tempo que vai desde a fase do Brasil colonial até a contemporaneidade. A história da literatura que se lê nesses romances reforça o caráter histórico da literatura, numa quebra de braço em que não há vencedores ou vencidos: a literatura garante seu estatuto e a história mostra, enfim, por que todos somos históricos.

3 - A história da literatura que decorre da leitura de um corpus constituído por narrativas de ficção que contemplam o período mais amplo de nossa ficção faz-se através da voz de um narrador: não do historiador, mas do ficcionista, concedendo originalidade ao discurso historiográfico. Lida nessa perspectiva, cabe à ficção (ou seja 
Rev. ANPOLL, n. 16, p. 225-240, jan./jun. 2004.

à literatura), a função da história. É o escritor, com sua palavra, quem recupera o passado e lhe dá sentido, selecionando e a apresentando os eventos dentro da linha do tempo

4 - A história da literatura que emana desse conjunto diz muito da nossa relação com o passado: preservamos do passado apenas aquilo que queremos preservar, já ensinou Paul Ricoeur. Assim, o que guardamos dos tempos já vividos é revelador da importância que atribuimos a esse passado. Mesclam-se nos textos ficcionais a voz do narrador contemporâneo com a voz do escritor distante no tempo e, nesse entrecruzamento, origina-se o novo texto. Nessa nova composição (a obra de ficção), passado, presente e futuro vivem o momento único da sua reunião: lido pelo leitor atual o passado deixa de ser aquele passado para se tornar o passado do presente e, desse presente do presente, remete ao futuro do nosso presente, por aquilo que nós formos capazes de legar à posteridade.

Eis aí um enredo para uma possivel história narrativa da literatura brasileira. Mescla de ficção e história, a história da literatura que se lê acima sugere muitas interpretações e diversificadas leituras, mas ensina, sobretudo, que história e literatura, duas senhoras tão intrigantes ${ }^{8}$ quanto amigas, muito têm a revelar quando, a quatro mãos, colaboram para tecer a complexa rede da historiografia.

\begin{abstract}
RÉSUME: Cet article fait la proposition de l'écriture d'une histoire de la littérature à partir d'un corpus constitué de romans brésiliens publiés dans les dernières années du XXe. siècle. Ces romans ont comme personnages de fiction des auteurs de la littérature brésilienne qui ont vécu et ont produit leurs oeuvres dans différents moments de notre histoire.
\end{abstract}

MOTS-CLÉ: romans brésiliens; histoire de la littérature.

8 A expressāo foi utilizada por Marisa Lajolo, no titulo do capítulo de sua autoria, constante do livro História da Literatura: ensaios, cuja referência encontra-se ao final deste trabalho. 
Moreira, Maria Eunice. Uma história (romanceada) da literatura brasileira.

\section{BIBLIOGRAFIA}

Antonio, João (1977). Calvário e porres do pingente Afonso Henriques de Lima Barreto. Rio de Janeiro: Civilização Brasileira.

BARReto, Antonio (2000). A barca dos amantes. Belo Horizonte: Lê.

Brasil, Luiz Antonio De Assis (1987). Os cães da Província. Porto Alegre: Mercado Aberto.

CAstro, Ruy (2000). Bilac vê estrelas. São Paulo: Companhia das Letras. Ferreira, Luzilá Gonçalves (1993). Os rios turvos. Rio de Janeiro: Rocco.

LAJOLO, Marisa (1994). Literatura e história da literatura: senhoras muito intrigantes. In: MALARD, Leticia et alii. História da literatura: ensaios. Campinas: Ed. da Unicamp. p. 19-36.

Maranhāo, Haroldo (1991). Memorial do fim. (A morte de Machado de Assis): romance. São Paulo: Marco Zero.

Martins, Sebastião (1990). A dança da serpente: romance. Belo Horizonte: Lê. Miranda, Ana (1995). A última quimera. São Paulo: Companhia das Letras.

Miranda, Ana. Clarice. O tesouro de minha cidade (1996). Rio de Janeiro: Relume-Dumará.

Miranda, Ana. Dias e dias: romance (2002). São Paulo: Companhia das Letras.

Miranda, Ana. Boca do inferno: romance (1989). São Paulo: Companhia das Letras.

Perkins, David (1999). História da literatura e narração. Cadernos do Centro de Pesquisas Literárias da PUCRS, Porto Alegre, v. 3, n. 1. Série Traduções.

Santiago, Silviano. Em liberdade: uma ficção de Silviano Santiago, 1981.

VILAR, Gilberto. O primeiro brasileiro: Bento Teixeira: poeta. São Paulo: Marco Zero, 1995. 